\title{
Correction to: Modeling of tumor response to macrophage and T lymphocyte interactions in the liver metastatic microenvironment
}

\author{
Louis T. Curtis $^{1} \cdot$ Susanne Sebens $s^{2,3} \cdot$ Hermann B. Frieboes ${ }^{1,4,5}$
}

Published online: 5 January 2021

(c) Springer-Verlag GmbH Germany, part of Springer Nature 2020

Correction to: Cancer Immunology, Immunotherapy https://doi.org/10.1007/s00262-020-02785-4

The original version of this article unfortunately contained a mistake. The "Grant Support" in the Pubmed database is showing a grant (R15CA203605/CA/NCI NIH HHS/United States).

The original article has been corrected.

Publisher's Note Springer Nature remains neutral with regard to jurisdictional claims in published maps and institutional affiliations.

The original article can be found online at https://doi.org/10.1007/ s00262-020-02785-4.

\section{Hermann B. Frieboes}

hbfrie01@louisville.edu

1 Department of Bioengineering, University of Louisville, Lutz Hall 419, Louisville, KY 40292, USA

2 Institute for Experimental Cancer Research, Christian-Albrechts-University Kiel (CAU), Kiel, Germany

3 University Medical Center Schleswig-Holstein (UK-SH), Campus Kiel, Kiel, Germany

4 Center for Predictive Medicine, University of Louisville, Louisville, KY, USA

5 James Graham Brown Cancer Center, University of Louisville, Louisville, KY, USA 